\title{
Investigation of Benzothiazole Derivatives as Corrosion Inhibitors for Mild Steel
}

\author{
K. Parameswari, ${ }^{a, *}$ S. Chitra, ${ }^{a}$ A. Selvaraj, ${ }^{b}$ S. Brindha ${ }^{a}$ and M. Menaga ${ }^{a}$ \\ ${ }^{a}$ PSGR Krishnammal College for Women, Coimbatore, India \\ ${ }^{b}$ CBM College, Coimbatore, Tamil Nadu, India
}

Received 2 February 2012; accepted 30 April 2012

\begin{abstract}
The influence of benzothiazole derivatives on corrosion inhibition of mild steel in $1 \mathrm{M}$ $\mathrm{H}_{2} \mathrm{SO}_{4}$ was studied by weight loss, potentiodynamic polarization and AC-impedance techniques. The synergistic effect by the addition of halide ions had been studied. The experimental results showed that the inhibition efficiency increases with increasing inhibitor concentration, but decreases with increasing temperature; potentiodynamic polarization curves showed that benzothiazole derivatives acted as cathodic inhibitors in $1 \mathrm{M} \mathrm{H}_{2} \mathrm{SO}_{4}$. This was supported by the impedance measurements which showed a change in the charge transfer resistance and double layer capacitance, indicating adsorption of Benzothiazole derivatives on the mild steel surface. Atomic absorption spectroscopy studies showed that the inhibition efficiency increases with increasing inhibitor concentration.
\end{abstract}

Keywords: benzothiazoles, AC-impedance, potentiodynamic polarization, corrosion inhibitor.

\section{Introduction}

Use of inhibitors is one of the most universal and economical measures to combat corrosion of metals. When present in small quantities in an aggressive medium they retard corrosion by bringing about changes in the surface condition of a metal. This work deals with the synthesis of hydrazino benzothiazole derivatives and evaluation of their anticorrosive performance for mild steel in acid medium. Benzothiazole consists of a 5-membered-1,3-thiazole ring fused to a benzene ring. The atoms of the bicycle and the attached substituents are coplanar,

\footnotetext{
* Corresponding author. E-mail: parampps@yahoo.co.in
} 


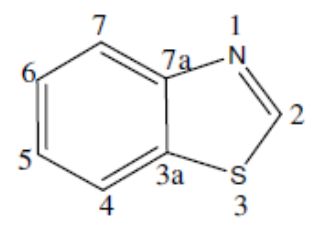

This heterocyclic scaffold can be readily substituted at the unique methyne centre in the thiaozle ring. It is thermally stable and has numerous applications in dyes such as thioflavin. Some drugs contain this group, eg. riluzole. A derivative of benzothiazole is the light emitting component of luciferin in fireflies.

The benzothiazole ring is a potential component in non-linear optics [1]. Many benzothiazole derivatives have been used as photostabilisers and metal complexing agents [2] and are non-toxic. Singh et al., [3] have reported that urea and thiourea derivatives are potential corrosion inhibitors. Therefore it is thought worth while to combine the two moieties viz, benzothiazole and thiourea/urea to get some novel, potential corrosion inhibitors for metals.

The aim of this work is to study the influence on the corrosion inhibition of mild steel in acid solutions of benzothiazole derivatives, which possess sulphur and nitrogen atoms in the heterocyclic structure. Weight loss measurements, effect of temperature, potentiodynamic polarization, and AC-impedance studies were carried out to evaluate the mechanism of corrosion inhibition. Synergistic effect of halide ions has also been studied.

\section{Experimental}

Mild steel strips with the composition $\mathrm{C}=0.084 \%, \mathrm{Mn}=0.369 \%, \mathrm{Si}=0.129 \%$, $\mathrm{P}=0.025 \%, \mathrm{~S}=0.027 \%, \mathrm{Cr}=0.022 \%, \mathrm{Mo}=0.011 \%, \mathrm{Ni}=0.013 \%, \mathrm{Fe}=\mathrm{Rest} \%$ and size of $3 \times 1 \times 0.05 \mathrm{~cm}$ were used for weight loss studies. The electrode was polished using a sequence of emery papers of different grades and then degreased with acetone. 1,3-benzothiazol-2-amine was synthesized by reported method [4] and purified by recrystalization. 2-substituted benzothiazole derivatives $(2 \mathrm{~b}, 2 \mathrm{c})$ were prepared by refluxing 1,3-benzothiazol-2-amine with hydrazine derivatives in presence of hydrochloric acid in ethanol for 2 hours. The fine crystalline solid was washed with water and recrystallised from ethanol.

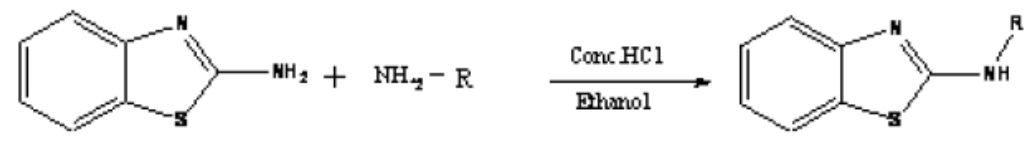

$2 \mathrm{a}$

$2 b, 2 c$

\begin{tabular}{ccl}
\hline Compound & $\mathrm{R}$ & Name of the compound \\
\hline $2 \mathrm{a}$ & - & Benzothiazole-2-amine (ABT) \\
$2 \mathrm{~b}$ & $-\mathrm{NH}-\mathrm{CS}-\mathrm{NH}-\mathrm{NH}_{2}$ & Benzothiazole-2-yl-thiocarbohydrazide (TCHBT) \\
$2 \mathrm{c}$ & $-\mathrm{NH}-\mathrm{CS}-\mathrm{NH}_{2}$ & Benzothiazole-2-yl-thiosemicarbazide (TSCBT) \\
\hline
\end{tabular}


The synthesized compounds were characterized by IR spectroscopy. The acid solution ( $1 \mathrm{M} \mathrm{H}_{2} \mathrm{SO}_{4}$ ) was prepared by dilution of analytical grade $\mathrm{H}_{2} \mathrm{SO}_{4}$ with distilled water. Mild steel specimens weighed previously were suspended in 100 $\mathrm{mL}$ of inhibited and uninhibited acid solutions for 3 hours. At the end of the period, specimens were taken out, well washed with running water, dried and finally weighed. Inhibition efficiency was calculated from the weight losses of specimens in the absence and presence of the inhibitor. The loss in weight was calculated at different temperatures from 303-333 K.

The electrochemical studies were carried out using a three electrode cell assembly at room temperature. Mild steel rod embedded in Teflon with exposed bottom area of $0.785 \mathrm{~cm}^{2}$ was used for electrochemical measurements. Platinum was used as counter electrode and saturated calomel electrode as reference electrode. The electrochemical measurements were carried out using a PARSTAT Electrochemical Analyser Model (2273). The impedance measurements were carried out in the frequency range of $10 \mathrm{KHz}$ to $0.01 \mathrm{~Hz}$ with signal amplitude of $10 \mathrm{mV}$. The double layer capacitance $\left(\mathrm{C}_{\mathrm{dl}}\right)$ and charge transfer resistance $\left(R_{c t}\right)$ were obtained from Nyquist plots. The Tafel polarization measurements were made after EIS for a potential range of $-200 \mathrm{mV}$ to $+200 \mathrm{mV}$ with respect to open circuit potential at a scan rate of $1 \mathrm{mV} / \mathrm{sec}$; the $\mathrm{I}_{\text {corr }}, \mathrm{E}_{\text {corr }}$, Tafel slopes $b_{a}$ and $b_{c}$ were obtained from the Tafel plots.

\section{Results and discussion}

\section{Weight loss measurements}

Table 1 gives the values of inhibition efficiency for different concentration of benzothiazole derivatives in $1 \mathrm{M} \mathrm{H}_{2} \mathrm{SO}_{4}$. It can be seen from the table that benzothiazole derivatives efficiently inhibit the corrosion of mild steel in $1 \mathrm{M}$ $\mathrm{H}_{2} \mathrm{SO}_{4}$ solution. This is due to the presence of heteroatoms like sulphur and nitrogen. Weight loss measurements revealed that corrosion inhibition efficiency of the benzothiazole derivatives increases on increasing the concentration.

\section{Influence of temperature and thermodynamic parameters}

Table 2 gives the inhibition efficiency values obtained by weight loss method at various temperatures. It is evident that inhibition efficiency decreases with temperature. But with TCHBT and TSCBT the inhibition efficiency does not fall much and they display about $80 \%$ efficiency even at $333 \mathrm{~K}$. For the present set of compounds the decrease in inhibition efficiency may be attributed to desorption and dissolution of inhibitors in the aggressive medium. Higher inhibition efficiency of sulphur compound is due to the strong affinity of these compounds for transition metal surfaces and their limited solubility in the acid solution at higher temperature.

The Arrhenius plots for the corrosion rate of mild steel with and without the inhibitors in $1 \mathrm{M} \mathrm{H}_{2} \mathrm{SO}_{4}$ are shown in Fig. 1.

The $\mathrm{E}_{\mathrm{a}}$ values (calculated using Arrhenius plots) for the inhibited solutions are higher than those for uninhibited solution indicating that the corrosion reaction of 
mild steel is retarded by the benzothiazole derivatives. The free energy of adsorption process $\Delta \mathrm{G}^{0}$ values were calculated using the standard equation [5]. The results are given in Table 3 .

Table 1. Values of inhibition efficiencies for different concentrations of benzothiazole derivatives in $1 \mathrm{M} \mathrm{H}_{2} \mathrm{SO}_{4} 30 \pm 1{ }^{\circ} \mathrm{C}$.

\begin{tabular}{ccccc}
\hline $\begin{array}{c}\text { Name of } \\
\text { the inhibitor }\end{array}$ & $\begin{array}{c}\text { Concentration } \\
(\mathrm{mM})\end{array}$ & $\begin{array}{c}\text { Weight } \\
\text { loss }(\mathrm{g})\end{array}$ & $\begin{array}{c}\text { Inhibition } \\
\text { efficiency }(\%)\end{array}$ & $\begin{array}{c}\text { Corrosion } \\
\text { rate }(\mathrm{mpy})\end{array}$ \\
\hline Blank & 0.2163 & - & 5437.41 \\
Benzothiazole-2-amine & 0.5 & 0.1242 & 42.57 & 3122.17 \\
ABT & 1.0 & 0.0888 & 58.94 & 2232.28 \\
& 2.0 & 0.0787 & 63.61 & 1978.38 \\
& 3.0 & 0.0763 & 64.72 & 1918.05 \\
& 4.0 & 0.0390 & 81.96 & 980.39 \\
TCHBT & 5.0 & 0.0371 & 82.84 & 932.63 \\
\hline & Blank & 0.2163 & - & 5437.41 \\
& 0.5 & 0.0765 & 64.63 & 1923.07 \\
& 1.0 & 0.0664 & 69.30 & 1669.18 \\
& 2.0 & 0.0294 & 86.40 & 739.06 \\
& 3.0 & 0.0241 & 88.85 & 605.83 \\
& 4.0 & 0.0216 & 90.01 & 542.98 \\
& 5.0 & 0.0192 & 91.12 & 482.65 \\
\hline & Blank & 0.2163 & - & 5437.41 \\
& 0.5 & 0.0663 & 69.35 & 1666.66 \\
1.0 & 0.0284 & 86.87 & 713.92 \\
& 2.0 & 0.0279 & 87.10 & 701.35 \\
& 3.0 & 0.0261 & 87.93 & 656.35 \\
& 5.0 & 0.0224 & 89.64 & 563.09 \\
& 0.0201 & 90.71 & 505.27 \\
\hline
\end{tabular}

Table 2. Values of inhibition efficiencies and corrosion rate for different temperatures in the presence of $5 \mathrm{mM}$ concentration of benzothiazole derivatives in $1 \mathrm{M} \mathrm{H}_{2} \mathrm{SO}_{4}$.

\begin{tabular}{ccccc}
\hline $\begin{array}{c}\text { Name of the } \\
\text { inhibitor }\end{array}$ & Temperature (K) & Weight loss (g) & $\begin{array}{c}\text { Inhibition } \\
\text { efficiency (\%) }\end{array}$ & $\begin{array}{c}\text { Corrosion rate } \\
(\mathrm{mpy})\end{array}$ \\
\hline \multirow{3}{*}{ Blank } & 303 & 0.0721 & - & 5437.41 \\
& 313 & 0.1218 & - & 9185.5 \\
& 323 & 0.1328 & - & 10015.07 \\
ABT & 333 & 0.1847 & - & 13929.09 \\
\hline & 303 & 0.0123 & 82.94 & 927.60 \\
& 313 & 0.0470 & 61.41 & 3544.49 \\
TCHBT & 323 & 0.0894 & 32.68 & 6742.07 \\
& 333 & 0.1325 & 28.26 & 9992.44 \\
\hline & 303 & 0.0064 & 91.12 & 482.65 \\
TSCBT & 313 & 0.0112 & 90.80 & 844.64 \\
& 333 & 0.0148 & 88.86 & 1116.13 \\
& 303 & 0.0285 & 84.57 & 2149.31 \\
\hline
\end{tabular}




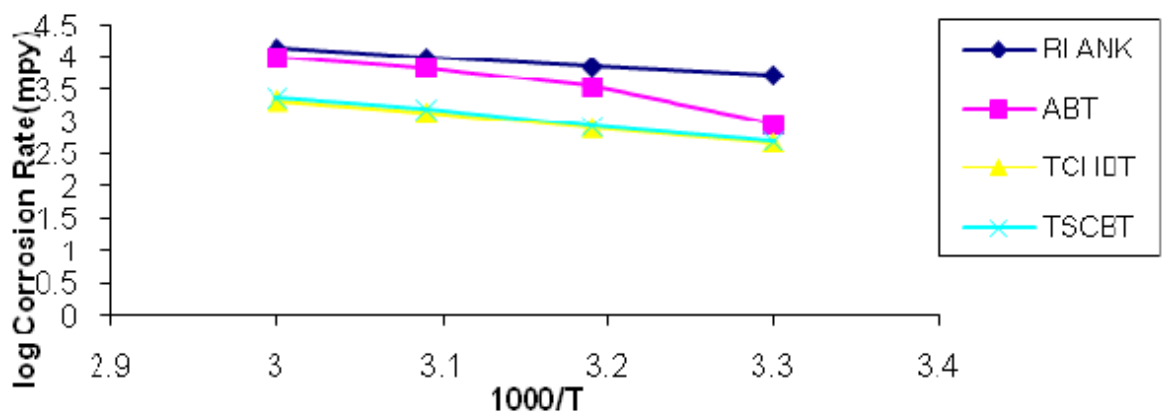

Figure 1. Arrhenius plots for mild steel in $1 \mathrm{M} \mathrm{H}_{2} \mathrm{SO}_{4}$ in the presence of $5 \mathrm{mM}$ concentration of benzothiazole derivatives at different temperatures

It was found that the $\Delta \mathrm{G}^{0}$ value is less than $-20 \mathrm{~kJ} / \mathrm{mol}$, indicating that the benzothiazole derivatives are physically adsorbed on the metal surface [6]. The negative value of $\Delta G^{0}$ shows a strong interaction of inhibitor molecules and spontaneous adsorption of inhibitors on the surface of the mild steel.

\section{EIS measurements}

The corrosion behavior of mild steel in $1 \mathrm{M} \mathrm{H}_{2} \mathrm{SO}_{4}$ in the absence and presence of various concentrations of the inhibitors was investigated by EIS technique. The Nyquist plot for TCHBT is shown in Fig. 2. The existence of a single semicircle in each plots shows that there was only a single charge transfer process controlling the corrosion. As can be seen from the figure the Nyquist plots are not perfect semicircles as expected from the theory of EIS and the difference can be explained as reported by Ozcan et al. [7]. In corrosion system the double layer formed at metal/solution interface can be represented by the electronic equivalent circuit diagram. The double layer is accepted to be equivalent to a condenser of capacity $C$. The electronic circuits which are especially designed that fit the equivalent circuit models yield perfect semicircular Nyquist plots and on these cells charge distribution is controlled by electrons. On the other hand, the Nyquist plots obtained for the corroding metal solution interface, charge distribution is controlled by electrons on the metal side and by ions on the solution side. Since ions are much larger than electrons, the equivalent ions to the charge on the metal will occupy quite a large volume on the solution side.

The impedance parameters such as $R_{t}$ and $C_{d l}$ are given in Table $4 . R_{t}$ value increases with concentration of the inhibitor. $C_{d l}$ value decreases with addition of inhibitor. Decreases in $\mathrm{C}_{\mathrm{dl}}$ are attributed to an increase in thickness of the electrical double layer with increase in concentration of the inhibitor. 
Table 3. Activation energies $\left(E_{a}\right)$ and free energy of adsorption $\left(\Delta G^{0}\right.$ ads $)$ for mild steel in the presence of benzothiazole derivatives in $1 \mathrm{M} \mathrm{H}_{2} \mathrm{SO}_{4}$.

\begin{tabular}{cccccc}
\hline $\begin{array}{c}\text { Name of the } \\
\text { inhibitor }\end{array}$ & $\mathrm{E}_{\mathrm{a}}(\mathrm{KJ} / \mathrm{mole})$ & \multicolumn{4}{c}{$\Delta \mathrm{G}^{\circ}$ ads } \\
& & $303 \mathrm{~K}$ & $313 \mathrm{~K}$ & $323 \mathrm{~K}$ & $333 \mathrm{~K}$ \\
\hline Blank & 26.74 & - & - & - & - \\
ABT & 52.32 & -10.0488 & -7.4732 & -4.5235 & -4.0851 \\
TCHBT & 41.50 & -11.9310 & -12.2235 & -12.0421 & -11.3756 \\
TSCBT & 42.90 & -11.8029 & -11.5136 & -11.0176 & -11.1409 \\
\hline
\end{tabular}

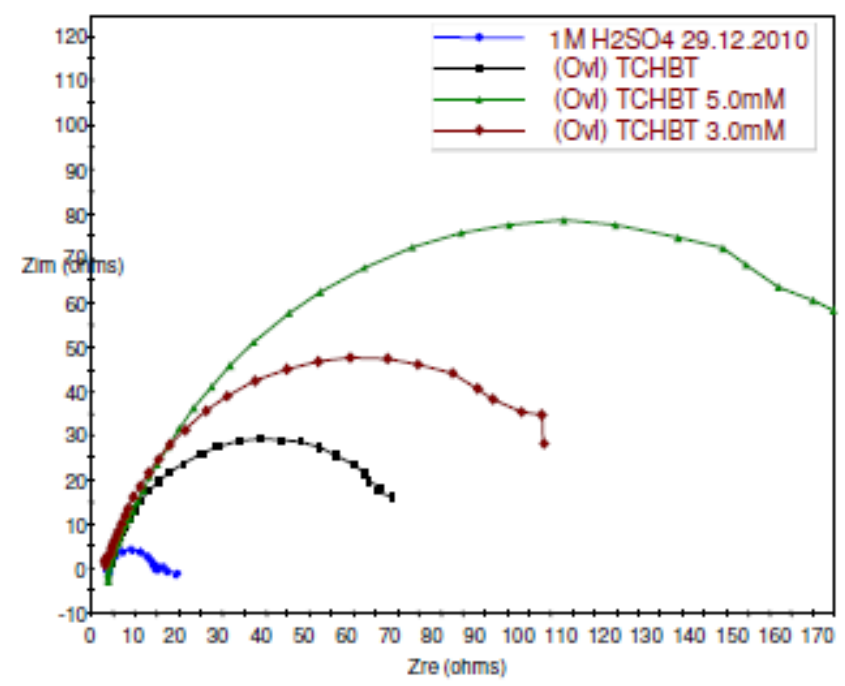

Figure 2. Impedance diagram of mild steel in the presence of TCHBT in $1 \mathrm{M} \mathrm{H}_{2} \mathrm{SO}_{4}$.

Table 4. Corrosion kinetic parameters of mild steel in the presence of benzothiazole derivatives in $1 \mathrm{M} \mathrm{H}_{2} \mathrm{SO}_{4}$ obtained by EIS method.

\begin{tabular}{ccccc}
\hline $\begin{array}{c}\text { Name of the } \\
\text { inhibitor }\end{array}$ & $\begin{array}{c}\text { Concentration } \\
(\mathrm{mM})\end{array}$ & $\begin{array}{c}\mathrm{R}_{\mathrm{t}} \\
\left.(\mathrm{ohm} \mathrm{cm})^{2}\right)\end{array}$ & $\begin{array}{c}\mathrm{C}_{\mathrm{dl}} \\
\left(\mu \mathrm{F} / \mathrm{cm}^{2}\right)\end{array}$ & $\begin{array}{c}\text { Inhibition } \\
\text { efficiency }(\%)\end{array}$ \\
\hline \multirow{2}{*}{ ABT } & Blank & 11.32 & 62.03 & - \\
& 0.5 & 16.05 & 19.25 & 29.47 \\
& 3.0 & 42.93 & 8.72 & 73.63 \\
TCHBT & 5.0 & 45.13 & 8.018 & 74.91 \\
\hline & 0.5 & 62.1 & 7.901 & 81.77 \\
TSCBT & 3.0 & 100.3 & 6.579 & 88.71 \\
& 5.0 & 161 & 3.241 & 92.96 \\
\hline
\end{tabular}

\section{Tafel polarization}

The electrochemical parameters for the corrosion of the experimental mild steel in $1 \mathrm{M} \mathrm{H}_{2} \mathrm{SO}_{4}$ containing the benzothiazole derivatives in various concentrations are given in Table 5. Shifting of corrosion potential $\mathrm{E}_{\text {corr }}$ towards more negative side indicated that these inhibitors act on the cathodic sites. Potentiodynamic 
polarization curves for the inhibitor TCHBT are given in Fig. 3, which reveals the shifting of $I_{\text {corr }}$ to lower current at higher concentration level $(5 \mathrm{mM})$, indicating more adsorption of the inhibitors and better inhibition performance. Analysis of the values of Tafel slopes $\left(b_{a}\right.$ and $\left.b_{c}\right)$ shows that there is significant increase in the values of cathodic Tafel slopes $b_{c}$, which indicates that these compounds are mixed type inhibitors, predominantly under cathodic control.

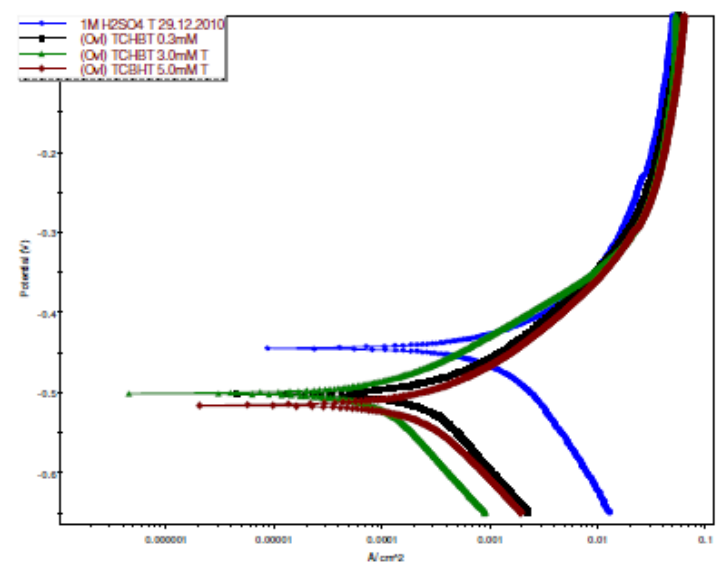

Figure 3. Polarisation curves for mild steel in the presence of TCHBT in $1 \mathrm{M} \mathrm{H}_{2} \mathrm{SO}_{4}$.

Table 5. Results of polarisation studies of mild steel in the presence of benzothiazole derivatives in $1 \mathrm{M} \mathrm{H}_{2} \mathrm{SO}_{4}$.

\begin{tabular}{|c|c|c|c|c|c|c|}
\hline \multirow{2}{*}{$\begin{array}{l}\text { Name of the } \\
\text { inhibitor }\end{array}$} & \multirow{2}{*}{$\begin{array}{l}\text { Concentration } \\
(\mathrm{mM})\end{array}$} & \multicolumn{2}{|c|}{$\begin{array}{l}\text { Tafel slopes } \\
(\mathrm{mV} / \mathrm{dec})\end{array}$} & \multirow{2}{*}{$\mathrm{E}_{\text {corr }}(\mathrm{mV})$} & \multirow{2}{*}{$\begin{array}{c}\mathrm{I}_{\mathrm{corr}} \\
\left(\mu \mathrm{Amp} / \mathrm{cm}^{2}\right)\end{array}$} & \multirow{2}{*}{$\begin{array}{l}\text { Inhibition } \\
\text { efficiency } \\
(\%)\end{array}$} \\
\hline & & $\mathrm{b}_{\mathrm{a}}$ & $b_{c}$ & & & \\
\hline \multirow{4}{*}{$\mathrm{ABT}$} & Blank & 80.69 & 113.18 & -444.62 & 1699 & - \\
\hline & 0.5 & 98.28 & 213.52 & -460.124 & 1063 & 37.43 \\
\hline & 3.0 & 98.28 & 160.13 & -514.08 & 541.8 & 68.11 \\
\hline & 5.0 & 91.30 & 256.17 & -431.08 & 309.2 & 81.80 \\
\hline \multirow{3}{*}{ TCHBT } & 0.5 & 85.60 & 207.66 & -501.24 & 371.3 & 78.14 \\
\hline & 3.0 & 74.47 & 199.46 & -500.56 & 300.8 & 82.29 \\
\hline & 5.0 & 80.48 & 181.71 & -498.33 & 78.08 & 95.40 \\
\hline \multirow{3}{*}{ TSCBT } & 0.5 & 83.22 & 196.05 & -500.84 & 489.9 & 71.16 \\
\hline & 3.0 & 86.74 & 155.74 & -503.26 & 236.5 & 86.08 \\
\hline & 5.0 & 81.66 & 140.68 & -502.20 & 109.5 & 93.55 \\
\hline
\end{tabular}

\section{Synergistic effect of halide ions}

The benzothiazole compounds reported in this work have 40-70\% inhibition efficiency at $0.5 \mathrm{mM}$ concentration. In order to enhance the inhibition efficiency at lower concentration, $\mathrm{KCl}, \mathrm{KBr}, \mathrm{KI}(1 \mathrm{mM})$ were added and the performance was evaluated by weight loss technique. The results are given in Table 6 which reveals that the inhibition efficiency of the benzothiazoles increased by about 20$25 \%$ on the addition of all the three halides. This behavior is attributed to the synergistic effect between added halide ions and the benzothiazoles. This synergistic effect may be due to co-adsorption of halide ions and the inhibitors which may be either competitive or co-operative. In competitive adsorption, the cation and anion are adsorbed at different sites on the surface. In co-operative 
adsorption, the anion is chemisorbed on the surface and the cation is adsorbed on a layer of the anion. Hence a close packed triple layer will form on the metal surface and inhibits the entry of iron ions to the solution. The benzothiazoles containing ' $\mathrm{N}$ ' atoms are readily protonated in aqueous acid medium. Since iron is positively charged in $\mathrm{H}_{2} \mathrm{SO}_{4}$ solution, the adsorption of protonated inhibitors is less. Hence in the absence of halide ions the benzothiazoles are adsorbed on the surface through their delocalized $\pi$-electrons, resulting in moderate inhibition efficiency. When halide ions are added, they are chemisorbed on the surface forming oriented dipoles with the negative end towards solution, thus increasing the adsorption of cationic inhibitors. The synergism is thus co-operative.

The synergism of halide ions with the benzothiazoles is found to be in the order $\mathrm{I}^{-}$ $>\mathrm{Cl}^{-}>\mathrm{Br}^{-}$. The reason for better synergism with $\mathrm{I}^{-}$ions may be due to the large size and ease of polarizability of $\mathrm{I}^{-}$ions which facilitates electron pair bonding with iron surface [8].

Table 6. Synergistic effect of $1 \mathrm{mM} \mathrm{KCl} / \mathrm{KBr} / \mathrm{KI}$ on the inhibition efficiency of benzothiazole derivatives by weight loss method.

\begin{tabular}{cccccc}
\hline \multirow{2}{*}{$\begin{array}{c}\text { Name of the } \\
\text { inhibitor }\end{array}$} & $\begin{array}{c}\text { Concentration } \\
(\mathrm{mM})\end{array}$ & $\begin{array}{c}\text { Without KCl, } \\
\text { KBr and KI }\end{array}$ & $\begin{array}{c}\text { With } \\
1 \mathrm{mM} \\
\mathrm{KCl}\end{array}$ & $\begin{array}{c}\text { With 1mM } \\
\mathrm{KBr}\end{array}$ & With 1mM \\
& & & & & $\mathrm{KI}$ \\
\hline \multirow{2}{*}{ ABT } & 0.5 & 42.57 & 61.94 & 69.17 & 67.05 \\
& 1.0 & 58.94 & 66.57 & 71.85 & 73.73 \\
& 2.0 & 63.61 & 70.57 & 74.88 & 78.09 \\
\hline \multirow{2}{*}{ TCHBT } & 0.5 & 64.63 & 86.79 & 89.48 & 92.60 \\
& 1.0 & 69.30 & 87.36 & 89.89 & 93.10 \\
& 2.0 & 86.40 & 88.98 & 90.14 & 93.76 \\
\hline \multirow{2}{*}{ TSCBT } & 0.5 & 69.35 & 77.82 & 78.47 & 86.20 \\
& 1.0 & 86.87 & 79.06 & 83.42 & 89.18 \\
& 2.0 & 87.10 & 85.83 & 89.03 & 92.21 \\
\hline
\end{tabular}

\section{Evaluation of inhibitor efficiency}

Comparison of IE of the compounds by all the techniques shows the following order:

\section{TCHBT $>$ TSCBT $>$ ABT}

All the compounds have,

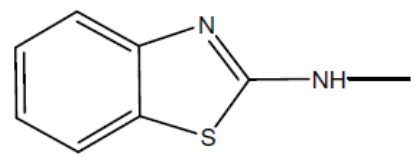

as common moiety. The variation in IE could therefore be due to the groups attached to the NH- nitrogen.

The parent benzothiazole ABT shows $82 \%$ efficiency (weight loss method).

The thiocarbonyl derivatives TCHBT and TSCBT display excellent inhibition properties even at low concentration. It has been considered that in thio 
compounds, the active centre is the $\mathrm{S}$ atom even if nitrogen atoms are present. Adsorption through sulphur could be predicted on the basis of 'Hard and Soft Acid Base' principle. The metal surface having $\mathrm{Fe}^{0}$ is a soft acid and $\mathrm{S}$ compounds are soft bases. An electrostatic attraction leading to a type of bonding occurs between $\mathrm{Fe}^{0}$ and $\mathrm{S}$ compound and is more favorable than the bonding between soft acid $\mathrm{Fe}^{0}$ and hard bases such as $\mathrm{O}$ and $\mathrm{N}$ centres.

According to Hoar and Holliday [9] the adsorption of an inhibitor on the surface will induce a partial negative charge at the point of attraction. There are two main ways by which the intensity of negative charge on the metal atom can be reduced: (i) back donation to sulphur atom, (ii) redistribution of charge at some cathodic sites. Donnelly et al. [10] have attributed the higher inhibition efficiency of $\mathrm{S}$ compounds to be due to presence of ' $\mathrm{d}$ ' orbitals of symmetry compatible with some of the 'd' orbitals of metal atoms; overlapping occurs forming a partial $\mathrm{d}_{\pi}-\mathrm{d}_{\pi}$ bond decreasing the residual positive charge on $\mathrm{S}$ and negative charge on Fe and strengthening the original electrostatic bond. Similar explanations can be given for the higher inhibition efficiency of TCHBT .
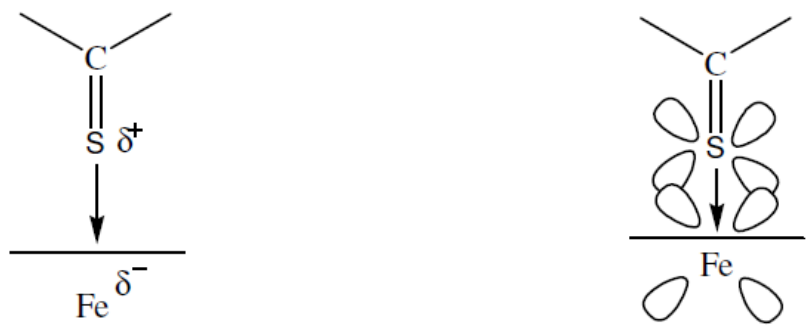

In TCHBT $\mathrm{C}=\mathrm{S}$ group acts as additional anchoring site for adsorption leading to stronger bond with metal surface and greater inhibiton.

These facts were also supported by the reports of Ozcan et al. [11] based on quantum chemical calculations. According to them, the highest value of the HOMO density were found in the vicinity of the sulphur atom, clearly indicating that the nucleophilic centre is ' $\mathrm{S}$ ' atom. Thus the bond with metal and $\mathrm{S}$ will be easily formed rather than with $\mathrm{N}$ or $\mathrm{C}$ atoms.

\section{Conclusion}

Benzothiazole derivatives have been found to be good inhibitors for mild steel corrosion in sulphuric acid media. Inhibition efficiency varies linearly with concentration. The optimum concentration of the inhibitor is $5 \mathrm{mM}$. The inhibitors act predominantly as cathodic type. The results obtained from weight loss, polarization and EIS methods match one another. The inhibitors obey Langmuir adsorption isotherm. 


\section{References}

1. P. Hrobarik, I. Sigmundova, P. Zahradnik, P. Kasak, V. Arion, E. Franz, K. Clays, J.Phys. Chem. C 114 (2010) 22289-22302.

2. $\quad$ E. Yousif, H. Adil, Y. Farina, J. Appl. Sci. Research 6 (2010) 879-882.

3. A. Gupta, M.M. Singh, Port. Electrochim. Acta 17 (1999) 21-43.

4. V. Kumar, R.K. Roy, V. Kumar, A. Kukshal, V.P. Yadav, J. Ind. Chem. Soc. 85 (2003) 333-335.

5. A.Yurt, A. Balaban, S. Ustun Kandemir, G. Bereket, B. Erk, Mat. Chem. Phy. 85 (2004) 420-426.

6. A.K. Singh, M.A. Quraishi, Corros. Sci. 52 (2010) 1529-1535.

7. M. Ozcan, I. Dehri, M. Erbil, Appl. Surf. Sci. 236 (2004) 155-164.

8. C. Jeyaprabha, S. Sathiyanarayanan, G. Venkatachari, Electrochimica Acta 5 (2006) 4080-4088.

9. T.P. Hoar, R.D. Holliday, J. Appl. Chem. 3 (1953) 502-513.

10. B. Donnelly, T.C. Downie, R. Grzeskowiak, Corros. Sci. 14 (1974) 597606.

11. M. Ozcan, I. Dehri, Prog. Org. Coatings 51 (2004) 181-187. 